REVIEW ARTICLE
H.J. Cloft
A. Rabinstein
G. Lanzino
D.F. Kallmes

\title{
Intra-Arterial Stroke Therapy: An Assessment of Demand and Available Work Force
}

\begin{abstract}
SUMMARY: Intra-arterial therapy is currently applicable to a small subset of patients with ischemic stroke, but it will likely have an expanding role as new devices are introduced. This review evaluates the demand for such therapy and the physician work force available to provide such therapy in the United States. The available literature was reviewed to assess how many patients might need intra-arterial therapy annually and how many skilled neurointerventionalists are available to provide intra-arterial therapy for acute stroke. The number of acute ischemic strokes in the United States that will be amenable to intra-arterial therapy can only be crudely estimated, but it is certainly less than 126,000 per year and will quite likely be no more than 20,000 cases per year. The future demand for intra-arterial reperfusion techniques may change, but the number of patients who require intra-arterial thrombolysis is currently quite low. The overall number of neurointerventionists is currently adequate, though there might be local shortages.
\end{abstract}

I schemic stroke is a complex disease with many forms and many corresponding treatments that must be tailored to the patient. The consensus guidelines from the American Heart Association and American Stroke Association regarding acute ischemic stroke treatment mentions intra-arterial therapy as one of many tools in the armamentarium of ischemic stroke therapies. ${ }^{1}$ Intra-arterial therapy is currently applicable to a small subset of patients with ischemic stroke, but it will likely have an expanding role as new devices are introduced. These expanding applications of intra-arterial therapy for ischemic stroke lead to speculation regarding the availability of a sufficient number of operators to treat these patients in the United States. $^{2}$

To address this issue of demand and available work force for intra-arterial ischemic stroke therapy, we must analyze the number of patients with ischemic stroke who might need this technique of treatment as well as the number of physicians who might be needed to provide it. We have no direct way to measure the number of ischemic strokes that might be amenable to intra-arterial therapy in the near future. This is because there are 2 major limitations in the analysis: 1) a lack of clear definition of which patients with ischemic stroke will be candidates for intra-arterial therapy, and 2) a lack of epidemiologic data to estimate how many patients are in various subgroups that might be deemed appropriate for intra-arterial therapy. There are also challenges in estimating the number of physicians who might be needed to provide intra-arterial ischemic stroke therapy in the United States. Despite these limitations, some reasonable estimates on the basis of currently available information can be made. The following is a review of the available information that can be used to estimate both a demand for intra-arterial ischemic stroke therapy and the work force available to provide such therapy.

From the Departments of Radiology (H.J.C., G.L., D.F.K.), Neurosurgery (H.J.C., G.L., D.F.K.), and Neurology (A.R.), Mayo Clinic, Rochester, Minn.

Please address correspondence to Harry J. Cloft, MD, Mayo Clinic, 200 First St SW, Rochester, MN 55905; e-mail: cloft.harry@mayo.edu

Indicates open access to non-subscribers at www.ajnr.org

DOI 10.3174/ajnr.A1462

\section{Who Needs Intra-Arterial Ischemic Stroke Therapy?}

Intra-arterial therapy has been shown to be efficacious in opening occluded arteries in some patients with severe ischemic stroke. ${ }^{3-6}$ However, far from all patients with ischemic stroke are candidates for intra-arterial stroke therapy. Only patients with occlusion of relatively large intracranial arteries typically undergo recanalization intra-arterially. Potential benefit of intra-arterial therapy must be balanced against potential risk. The risks are not trivial, as intra-arterial therapy has been associated with a $5 \%$ to $7 \%$ risk for clinically significant procedural complications $s^{4,7}$ and a $6 \%$ to $15 \%$ risk for symptomatic intracranial hemorrhage. ${ }^{4-9}$ For patients with less severe stroke symptoms, the risks for intra-arterial therapy almost certainly outweigh the benefits. Patients with a National Institutes of Health Stroke Score (NIHSS) of less than 10 who are treated with intravenous recombinant tissue plasminogen activator (rtPA) have an $82 \%$ chance of a good outcome (modified Rankin Scale, 0-2), a 3\% chance of symptomatic hemorrhage, and a $1 \%$ chance of death. ${ }^{10}$ Such patients with an NIHSS of less than 10 are quite unlikely to benefit from intra-arterial therapy, as they typically have normal results on cerebral angiograms or distal or recanalizing emboli. ${ }^{11-13}$ The Interventional Management of Stroke (IMS) $\mathrm{I}^{8}$ and IMS II ${ }^{5}$ trials treated patients with NIHSS of 10 or more, and trials of the Merci Retrieval System (Concentric Medical, Mountain View, Calif) treated patients with NIHSS of 8 or more m $^{3,4,14}$ and 10 or more. ${ }^{15}$ Major stroke centers offering ischemic stroke therapy tend to follow this practice of reserving intra-arterial therapy for major strokes. ${ }^{16-23}$

Intra-arterial therapy has not yet been shown to be definitively better than intravenous therapy in terms of neurologic outcomes. Table 1 shows comparative data from major studies completed thus far. In IMS I and IMS II, comparisons were made between patients treated with combined intravenous and intra-arterial therapy, and patients matched for age and NIHSS from the National Institute of Neurological Disorders and Stroke trial. These outcome data for patients treated with intravenous placebo and intravenous rtPA are also included in Table 1. The data in Table 1 indicate that much improvement could be made in outcomes from ischemic stroke therapies. More data are necessary to clearly define the role of intraarterial therapy techniques in ischemic stroke therapy.

IMS I and IMS II did not include enough patients to show 


\begin{tabular}{|c|c|c|c|c|c|}
\hline Study & $\begin{array}{l}\text { Mean Baseline } \\
\text { NIHSS }\end{array}$ & $\begin{array}{r}\text { Recanalization } \\
\text { (TIMI } 2 \text { or } 3 \text { ) }\end{array}$ & $\begin{array}{l}\text { Good Outcome at } 90 \text { Days } \\
\text { (mRS 0-2) }\end{array}$ & $\begin{array}{l}\text { Mortality at } \\
90 \text { Days }\end{array}$ & $\begin{array}{c}\text { Symptomatic } \\
\text { ICH }\end{array}$ \\
\hline \multicolumn{6}{|l|}{ Intra-arterial therapy } \\
\hline PROACT $^{9}$ & 17 & $58 \%$ & NA & $27 \%$ & $15 \%$ \\
\hline PROACT $\|^{6}$ & 17 & $66 \%$ & $40 \%$ & $25 \%$ & $10 \%$ \\
\hline$|M S-|^{8}$ & 18 & $56 \%$ & $43 \%$ & $16 \%$ & $6 \%$ \\
\hline IMS-II & 19 & $60 \%$ & $46 \%$ & $16 \%$ & $10 \%$ \\
\hline $\mathrm{MERCl}^{7}$ & 22 & $46 \%$ & $28 \%$ & $44 \%$ & $8 \%$ \\
\hline Multi MERCI ${ }^{4}$ & 19 & $68 \%$ & $36 \%$ & $34 \%$ & $10 \%$ \\
\hline Penumbra pivotal study & 18 & $82 \%$ & $25 \%$ & $33 \%$ & $11 \%$ \\
\hline \multicolumn{6}{|l|}{ Nonarterial therapy } \\
\hline $\mathrm{PROACT}^{9}$ & 19 & $14 \%$ & NA & $43 \%$ & $7 \%$ \\
\hline PROACT $\|^{2}$ control & 17 & $18 \%$ & $25 \%$ & $27 \%$ & $2 \%$ \\
\hline NINDS placebo*5 & 18 & NA & $28 \%$ & $24 \%$ & $1 \%$ \\
\hline NINDS IV rtPA*5 & 18 & NA & $39 \%$ & $21 \%$ & $7 \%$ \\
\hline
\end{tabular}

Note:-NIHSS indicates National Institutes of Health Stroke Scale; TIMI, Thrombolysis in Myocardial Infarction trial; ICH, intracranial hemorrhage; mRS, modified Rankin Scale; PROACT, Prolyse in Acute Cerebral Thromboembolism trial; IMS, Interventional Management of Stroke trials; MERCI, Mechanical Embolus Removal in Cerebral Ischemia trials; NINDS, Nationa Institute of Neurological Disorders and Stroke; NA, not available.

* NINDS is subgroup of patients with an NIHSS of 10 or more.

a statistically significant benefit to intra-arterial therapy vs intravenous therapy, nor were they designed to do so. IMS III is now underway and will randomly assign patients to receive intravenous therapy or a combination of intravenous and intra-arterial therapy, with the hope of demonstrating clear evidence of benefit of intra-arterial therapy. ${ }^{24}$

According to data from major studies of intra-arterial therapy, only $28 \%$ to $46 \%$ of patients treated achieve a good neurologic outcome (Table 1). That means that $54 \%$ to $72 \%$ have a bad outcome despite intra-arterial therapy, including $16 \%$ to $44 \%$ who are dead at 90 days (Table 1). Some proportion of the reported low efficacy of these trials likely results from imperfect recanalization rates, ranging from $46 \%$ to $66 \%$, but much is undoubtedly because of infarctions that were already completed before the initiation of intra-arterial therapy. Many patients presenting less than 8 hours from symptom onset clearly do not have salvageable brain because of poor collaterals. ${ }^{25}$ If good, rapid imaging capable of identifying ischemic penumbra were available to determine salvageable brain tissue (such as diffusion-weighted or perfusion-weighted MR imaging ${ }^{26-36}$ or CT perfusion ${ }^{37,38}$ ), intra-arterial interventions for ischemic stroke could be reduced by perhaps half because it would be possible to determine that infarction is complete before these patients are moved to an interventional suite. This would be of benefit to patients because it spares them futile, aggressive interventions. This is currently a topic of intense research, which hopefully will yield clinically useful triage techniques. The Magnetic Resonance and Recanalization of Stroke Clots Using Embolectomy study is a trial underway that may give insight into the value of MR in triaging patients with ischemic stroke. $^{39}$

\section{How Many Patients Will Need Intra-arterial Therapy?}

It has been estimated that approximately $0.07 \%{ }^{40}$ to $0.17 \%{ }^{22}$ of all patients with ischemic stroke received intra-arterial therapy in the United States from 1999 and 2002, which would amount to only approximately 1100 patients. The Merci Retrieval System (Concentric Medical) ${ }^{3,4}$ and Penumbra System (Penumbra, Alameda, Calif) ${ }^{41}$ were recently approved by the US Food and Drug Administration for the treatment of ischemic stroke, and use of these devices may have increased the number of patients treated with intra-arterial therapy. Thus, 1100 patients per year is the absolute minimal estimate of the number of patients in the United States who would be treated with intra-arterial therapy for ischemic stroke.

To estimate the other extreme, we can start with the overall number of strokes per year in the United States, which is a reasonably well-defined number of 700,000 to 750,000 strokes per year. ${ }^{42-46} \mathrm{An}$ important point of confusion in the literature on acute ischemic stroke is the common, hyperbolic use of this number. This statistic is inappropriate in discussions specifically focused on treatment of acute ischemic stroke because it includes all types of stroke and all levels of severity and thus leads to absurd leaps in logic and assumptions that all or most of these strokes need recanalization therapy. Approximately $14 \%$ of these patients with stroke have intracranial hemorrhage, including subarachnoid hemorrhage; $4 \%$ have transient ischemic attack; and 1\% have "late effects of cerebrovascular disease." ${ }^{\$ 5,46}$ Starting with 750,000 strokes per year and subtracting $19 \%$ to correct for cases that are not due to acute ischemia yields 645,000 ischemic strokes per year. This estimate is supported by a recent study by Qureshi et $\mathrm{al},{ }^{47}$ which determined that there were approximately $1,260,000$ hospital admissions for ischemic stroke in the United States in 2000 and 2001 (ie, 630,000 admissions for ischemic stroke per year).

Therefore, if we settle on an estimate of 645,000 ischemic strokes per year, how many patients will need intra-arterial therapy? Approximately $17 \%$ of ischemic strokes are from lacunar infarctions, ${ }^{48,49}$ which reduces the number of potential intra-arterial therapy cases to 535,000. However, the nonlacunar infarctions are not defined well enough to allow us to determine what fraction of these might be amenable to endovascular therapy. Another way to refine the 645,000 ischemic strokes per year is on the basis of severity. As discussed above, only patents with severe ischemic stroke (ie, NIHSS $\geq 10$ ) are likely to benefit from intra-arterial therapy. Of acute ischemic strokes evaluated by the Greater Cincinnati/Northern Kentucky Stroke Team in 2005, 20\% had an NIHSS of 10 or greater (Thomas Tomsick, unpublished data, 2008). Extrapolating this percentage to the entire US population would lead to an estimate of 126,000 patients with such severe acute ischemic strokes in the United States annually. Not all of these patients 
would be candidates for endovascular therapy, but this would be the size of the pool of patients with severe acute ischemic stroke from which patients undergoing endovascular therapy would be drawn; therefore, it is a theoretic maximum of endovascular therapy candidates. It is not possible to narrow the number of potential interventions for intra-arterial ischemic stroke further given the limitations of available epidemiologic data. However, we can further refine our estimate by looking at available data on patients treated with intravenous rtPA for acute ischemic stroke.

The treatment of stroke as an emergency in the United States has been evolving since the US Food and Drug Administration approval of intravenous rtPA for ischemic stroke in 1996. Approximately 12,000 patients received intravenous rtPA for ischemic stroke in the United States during 2004, ${ }^{50}$ which represents $2 \%$ of all patients with ischemic stroke. Studies have shown that even with very active and organized emergency medical services and stroke teams, this number only increases to approximately $9 \% .{ }^{51}$ Many of the patients treated with intravenous lysis do fine and do not require intra-arterial intervention, but this is hard to quantify. So if 645,000 ischemic strokes per year occur in the United States, and no more than $9 \%$, or 58,000 , would qualify for intravenous rtPA in the most aggressive stroke management setting, then the number of potential candidates for intra-arterial stroke therapy is well likely to be less 58,000 per year in the United States.

Much effort has already been put into improving emergency medical services for patients with stroke. ${ }^{52}$ Delays in presentation to a hospital that provides acute stroke therapy can certainly disqualify many patients from treatments such as intravenous rtPA and intra-arterial therapy. Approximately $25 \%$ to $59 \%$ of patients with stroke arrive at an emergency department within 3 hours of onset of symptoms, and 35\% to $66 \%$ arrive within 6 hours. ${ }^{53}$ On the basis of these numbers, programs aimed at developing the general public's awareness of stroke symptoms and at minimizing the delay in transporting the patient to an appropriate medical center might be expected to increase the number of patients who might be treatable with intra-arterial therapy. Such an aggressive educational program in Texas increased the number of patients treated with intravenous thrombolysis by a factor of $4 .{ }^{51} \mathrm{Im}-$ proving the access of patients to acute stroke centers and educating physicians and patients to respond to stroke as an emergency can increase the demand for intra-arterial thrombolysis; however, this process will be gradual and must be dealt with primarily at the local level.

Conversely, as noted above, improvements in triage with use of new imaging modalities, such as with MR imaging or CT perfusion, may indicate absence of ischemic penumbra in perhaps half of all cases for which intra-arterial therapy is contemplated. However, penumbra imaging is not yet standard in the evaluation of patients with ischemic stroke.

\section{Who Provides Care for Patients with Acute Ischemic Stroke?}

The practice of acute stroke care is dependent on patient access to skilled physicians and technology in a stroke center committed to treat acute stroke as an emergency. Intravenous thrombolysis can be administered safely and effectively in small hospitals, preferably under the guidance of stroke spe- cialists. Subsequent acute stroke care should be provided in specialized stroke centers. Stroke centers should be able to care for patients with all subtypes of stroke, including hemorrhagic strokes that require treatment by a neurosurgeon. Expert-level care has been shown to improve the care of patients with acute stroke. ${ }^{54-56}$ Formal stroke center recognition can help to consolidate resources such as diagnostic capabilities and personnel trained to implement evidence-based practices, and also to bring public attention to the location of these centers of expertise. In 2000, the Brain Attack Coalition proposed 2 types of stroke centers: primary and comprehensive. ${ }^{57}$ A primary stroke center has the staffing, infrastructure, and programs necessary to stabilize and treat most patients with acute stroke. A comprehensive stroke center is defined as a facility with the staffing, infrastructure, and programs to diagnose and treat patients with stroke who require a high intensity of medical and surgical care, specialized tests, or interventional therapies. $^{58}$

In 2003, the Joint Commission began certifying primary stroke centers. There are now 401 primary stroke centers certified by the Joint Commission. ${ }^{59}$ This certification is based on the recommendations of the Brain Attack Coalition. ${ }^{57}$ The requirements for primary stroke center certification do not include availability of intra-arterial ischemic stroke therapy or a neurologist. They also do not include an on-site stroke unit or on-site neurosurgery, as it is understood that some primary stroke centers will stabilize patients and then transfer them to other centers for more advanced care. This paradigm is already being developed as a "drip-and-ship" approach, ${ }^{60}$ in which primary stroke centers initiate intravenous rtPA therapy and then transport patients to a comprehensive stroke center. With many primary stroke centers functioning with this "first stop" model, it is not reasonable to expect that all primary stroke centers will provide intra-arterial ischemic stroke therapy.

Recommendations for access to endovascular therapy were reserved for comprehensive stroke centers, which would offer a higher level of care than primary stroke centers. ${ }^{58}$ This recommendation is also in accordance with the guidelines for the early management of adults with ischemic stroke from the American Heart Association and American Stroke Association, which states that intra-arterial therapy "will be limited to those comprehensive stroke centers that have the resources and physician expertise to perform these procedures safely." ${ }^{1}$ The Joint Commission has not yet begun a program to certify comprehensive stroke centers. If comprehensive stroke center certification becomes a reality, it would be expected that primary stroke centers would refer more difficult patients to these centers. Many regional comprehensive stroke centers already exist in practice, but a formal certification and recognition process would be a significant advance in the development of a national system to address the needs of patients with stroke.

Epidemiologic statistics are bandied about, implying that huge numbers of patients with stroke are not getting appropriate care, ${ }^{2}$ but such implications completely ignore the experience of leading acute stroke centers and work done at such centers to improve stroke care. Single-center reports from well-developed stroke centers doing intra-arterial ischemic stroke therapy cases demonstrate a case rate of 3 to 30 cases per 
Table 2: Demand for thrombolysis in the United States based on the published literature

\begin{tabular}{|c|c|}
\hline Report & $\begin{array}{c}\text { Cases per Year } \\
\text { per Hospital* }\end{array}$ \\
\hline \multicolumn{2}{|c|}{ Intra-arterial treatment, multicenter trials } \\
\hline PROACT, $1998^{9}$ & $1(0-10)$ \\
\hline PROACT II, $1999^{6}$ & $1(0-17)$ \\
\hline EMS, $1999^{66}$ & $5(2-10)$ \\
\hline IMS-I, $2004^{8}$ & $7(0-27)$ \\
\hline MERCI, $2005^{7}$ & $3(0-9)$ \\
\hline IMS-II, $2007^{5}$ & $2(N A)$ \\
\hline Multi MERCI, $2008^{4}$ & $5(0-20)$ \\
\hline \multicolumn{2}{|c|}{ Intra-arterial treatment, single center } \\
\hline Barnwell et al, $1994^{19}$ & 7 \\
\hline Suarez et al, $1999^{18}$ & 15 \\
\hline Jahan et al, $1999^{67}$ & 5 \\
\hline Ernst et al, $2000^{20}$ & 17 \\
\hline Hill et al, $2002^{21}$ & 4 \\
\hline Ramee et al, $2004^{68}$ & 3 \\
\hline Choi et al, $2006^{22}$ & 9 \\
\hline Devlin et al, $2007^{23}$ & 30 \\
\hline Kim et al, $2007^{17}$ & 13 \\
\hline Wolfe et al, $2008^{16}$ & 15 \\
\hline \multicolumn{2}{|c|}{ Intravenous treatment, multicenter trials } \\
\hline NINDS, $1995^{69}$ & 20 \\
\hline ATLANTIS, $1999^{70}$ & 1 \\
\hline STARS, $2000^{71}$ & 4 \\
\hline \multicolumn{2}{|c|}{ Intravenous treatment, single center } \\
\hline Chiu et al, $1998^{72}$ & 30 \\
\hline Zweifler et al, $1998^{73}$ & 9 \\
\hline Grotta et al, $2001^{74}$ & 61 \\
\hline Kahn et al, $2005^{75}$ & 26 \\
\hline Wolfe et al, $2008^{16}$ & 45 \\
\hline Arenillas et $\mathrm{al}^{76}$ & 46 \\
\hline
\end{tabular}

Note:-PROACT indicates Prolyse in Acute Cerebral Thromboembolism trial; EMS, Emergency Management of Stroke trial; IMS, Interventional Management of Stroke trials; MERCI, Mechanical Embolus Removal in Cerebral Ischemia trials; NINDS, National Institute of Neurological Disorders and Stroke; ATLANTIS, Alteplase Thrombolysis for Acute Noninterventional Therapy in Ischemic Stroke trial; STARS, Standard Treatment with Alteplase
inter to Reverse Stroke study.

* Numbers in parentheses are ranges.

year per medical center (Table 2). These centers are national and international leaders in acute stroke intervention, so it is reasonable to assume that patients are being treated with an appropriately aggressive level of care. Also, as tertiary referral centers for patients with stroke, these hospitals would be expected to receive many more patients with strokes than hospitals that do not specialize in stroke. A number of multicenter trials of intra-arterial therapies for ischemic stroke have been performed. These trials give us some insight into the quantity of patients that might be treated with intra-arterial therapy at leading stroke centers. The highest enrollment rate for any hospital in any of these trials was 27 cases per year (Table 2). Even if rates of intra-arterial therapies were to go as high as rates of intravenous rtPA treatment of ischemic stroke, the rate would only go as high as 61 cases per year per hospital at the busiest of these tertiary centers (Table 2).

The delivery of stroke care is analogous to the delivery of trauma care, in that a regional system is needed that provides rapid, skilled care to as many people as is practical. A regional care model has also been applied to myocardial infarctions, but this has not been implemented on a national level as in trauma. ${ }^{61}$ Designated trauma centers have been developed throughout the United States. The number of level I trauma centers in the United States is $190 .{ }^{62}$ Perhaps similar-level comprehensive stroke centers might be designated in the future. If each of these comprehensive stroke centers were staffed by 2 neurointerventionists, then the total number of required neurointerventionists would be approximately 400 .

If each of an estimated 200 comprehensive stroke centers treated 100 patients per year with intra-arterial thrombolysis, 20,000 individuals would be treated annually in the United States. A rate of 100 patients per year per medical center is at least 3 times the rate of stroke centers that aggressively use intra-arterial therapy, and twice the rate of intravenous therapy at aggressive stroke centers (Table 2). That translates to $3 \%$ of the 645,000 patients hospitalized for acute ischemic stroke in the United States each year who could be treated with intra-arterial methods; this rate is twice the percentage of patients with acute stroke who qualified for intra-arterial thrombolysis in the Prolyse in Acute Cerebral Thromboembolism II study. $^{6}$

Although comprehensive stroke centers have not yet been officially designated as such, many US hospitals are currently operating in this capacity unofficially. Most centers with trained, specialized neurointerventionalists would likely meet the criteria for a comprehensive stroke center. In 2002, Suzuki et $\mathrm{al}^{63}$ identified 385 neurointerventionists in 238 hospitals covering 45 states. Suzuki et $\mathrm{al}^{63}$ determined that $99 \%$ of the total US population lived within 200 miles of a neurointerventional practice, and $82 \%$ lived within a 65 -mile radius. The Society of Neurointerventional Surgery (SNIS) is the largest society of practicing neurointerventionalists in the United States, with members representing neuroradiology, neurosurgery, and neurology. There were 301 senior members of the SNIS practicing in the United States in 2008. This number has increased by $50 \%$ (from 208) since 2001 . Not all neurointerventionalists are members of this society, so the actual number of practicing neurointerventionalists is undoubtedly higher. The number of neurointerventionalists can be expected to increase steadily as training programs continue to provide the necessary advanced training to neuroradiologists, neurosurgeons, and neurologists.

Because stroke is a major health problem, it makes sense that skilled care be available from neurologic experts. Qualification standards have already been published as agreed on by multidisciplinary groups of neurologists, neurosurgeons, and neuroradiologists who perform these procedures. ${ }^{64}$ The American College of Graduate Medical Education has also defined training standards for neurointervention. ${ }^{65}$ It is rather naive to assume that such advanced care can be delivered by physicians without expertise in the neurosciences. Each acute stroke center that offers intra-arterial ischemic stroke therapy needs to assure that this therapy is being offered by qualified individuals.

\section{Conclusions}

The number of acute ischemic strokes in the United States that will be amenable to intra-arterial therapy can only be crudely estimated, but it is certainly less than the total number of 126,000 severe acute ischemic strokes per year and quite likely to be no more than 20,000 cases per year. The future demand for intra-arterial reperfusion techniques may change, but the number of patients who require intra-arterial thrombolysis is currently quite low, and the number of neurointerventionists 
is currently grossly adequate. Each evolving acute stroke center will need to determine its own demand for intra-arterial reperfusion techniques and have an adequate supply of qualified neurointerventionists available to meet this demand.

\section{References}

1. Adams HP Jr, del Zoppo G, Alberts MJ, et al. Guidelines for the early management of adults with ischemic stroke: a guideline from the American Heart Association/American Stroke Association Stroke Council, Clinical Cardiology Council, Cardiovascular Radiology and Intervention Council, and the Atherosclerotic Peripheral Vascular Disease and Quality of Care Outcomes in Research Interdisciplinary Working Groups: The American Academy of Neurology affirms the value of this guideline as an educational tool for neurologists [published erratum appears in Circulation 2007;116:e515]. Circulation 2007;115:e478-534

2. White CJ, Cates CU, Cowley MJ, et al. Interventional stroke therapy: current state of the art and needs assessment. Catheter Cardiovasc Interv 2007;70:471-76

3. Smith WS. Safety of mechanical thrombectomy and intravenous tissue plasminogen activator in acute ischemic stroke. Results of the multi Mechanical Embolus Removal in Cerebral Ischemia (MERCI) trial, part I. AJNR Am J Neuroradiol 2006;27:1177-82

4. Smith WS, Sung G, Saver J, et al. Mechanical thrombectomy for acute ischemic stroke: final results of the Multi MERCI trial. Stroke 2008;39:1205-12

5. The Interventional Management of Stroke (IMS) II Study. Stroke 2007;38:2127-35

6. Furlan A, Higashida R, Wechsler L, et al. Intra-arterial prourokinase for acute ischemic stroke. The PROACT II study: a randomized controlled trial. Prolyse in Acute Cerebral Thromboembolism. JAMA 1999;282:2003-11

7. Smith WS, Sung G, Starkman S, et al. Safety and efficacy of mechanical embolectomy in acute ischemic stroke: results of the MERCI trial. Stroke 2005;36:1432-38

8. The IMS Investigators. Combined intravenous and intra-arterial recanalization for acute ischemic stroke: the Interventional Management of Stroke Study. Stroke 2004;35:904-11

9. del Zoppo GJ, Higashida RT, Furlan AJ, et al. PROACT: a phase II randomized trial of recombinant pro-urokinase by direct arterial delivery in acute middle cerebral artery stroke. PROACT Investigators. Prolyse in Acute Cerebral Thromboembolism. Stroke 1998;29:4-11

10. The NINDS Stroke Study Investigators. Recombinant tissue plasminogen activator for minor strokes: the National Institute of Neurological Disorders and Stroke rt-PA Stroke Study experience. Ann Emerg Med 2005;46:243-52

11. Tomsick T, Brott T, Barsan W, et al. Prognostic value of the hyperdense middle cerebral artery sign and stroke scale score before ultraearly thrombolytic therapy. AJNR Am J Neuroradiol 1996;17:79-85

12. Nakajima M, Kimura K, Ogata $\mathrm{T}$, et al. Relationships between angiographic findings and National Institutes of Health stroke scale score in cases of hyperacute carotid ischemic stroke. AJNR Am J Neuroradiol 2004;25:238-41

13. Fischer U, Arnold M, Nedeltchev K, et al. NIHSS score and arteriographic findings in acute ischemic stroke. Stroke 2005;36:2121-25

14. Flint AC, Duckwiler GR, Budzik RF, et al. Mechanical thrombectomy of intracranial internal carotid occlusion: pooled results of the MERCI and Multi MERCI Part I trials. Stroke 2007;38:1274-80

15. Gobin YP, Starkman S, Duckwiler GR, et al. MERCI 1: a phase 1 study of Mechanical Embolus Removal in Cerebral Ischemia. Stroke 2004;35:2848-54

16. Wolfe T, Suarez JI, Tarr RW, et al. Comparison of combined venous and arterial thrombolysis with primary arterial therapy using recombinant tissue plasminogen activator in acute ischemic stroke. J Stroke Cerebrovasc Dis 2008; 17:121-28

17. Kim D, Ford GA, Kidwell CS, et al. Intra-arterial thrombolysis for acute stroke in patients $\mathbf{8 0}$ and older: a comparison of results in patients younger than $\mathbf{8 0}$ years. AJNR Am J Neuroradiol 2007;28:159-63

18. Suarez JI, Sunshine JL, Tarr R, et al. Predictors of clinical improvement, angiographic recanalization, and intracranial hemorrhage after intraarterial thrombolysis for acute ischemic stroke. Stroke 1999;30:2094-100

19. Barnwell SL, Clark WM, Nguyen TT, et al. Safety and efficacy of delayed intraarterial urokinase therapy with mechanical clot disruption for thromboembolic stroke. AJNR Am J Neuroradiol 1994;15:1817-22

20. Ernst R, Pancioli A, Tomsick T, et al. Combined intravenous and intra-arterial recombinant tissue plasminogen activator in acute ischemic stroke. Stroke 2000;31:2552-57

21. Hill MD, Barber PA, Demchuk AM, et al. Acute intravenous-intra-arterial revascularization therapy for severe ischemic stroke. Stroke 2002;33:279-82

22. Choi JH, Bateman BT, Mangla S, et al. Endovascular recanalization therapy in acute ischemic stroke. Stroke 2006;37:419-24

23. Devlin TG, Baxter BW, Feintuch TA, et al. The Merci Retrieval System for acute stroke: the Southeast Regional Stroke Center experience. Neurocrit Care 2007;6:11-21
24. Tomsick TA. 2006: a stroke odyssey. AJNR Am J Neuroradiol 2006;27:2019-21

25. Christoforidis GA, Mohammad Y, Kehagias D, et al. Angiographic assessment of pial collaterals as a prognostic indicator following intra-arterial thrombolysis for acute ischemic stroke. AJNR Am J Neuroradiol 2005;26:1789-97

26. Schellinger PD, Fiebach JB, Jansen $O$, et al. Stroke magnetic resonance imaging within 6 hours after onset of hyperacute cerebral ischemia. Ann Neurol 2001;49:460-69

27. Cho AH, Sohn SI, Han MK, et al. Safety and efficacy of MRI-based thrombolysis in unclear-onset stroke. A preliminary report. Cerebrovasc Dis 2008; 25:572-79

28. Han MK, Kim SH, Ko SB, et al. Combined intravenous and intraarterial revascularization therapy using MRI perfusion/diffusion mismatch selection for acute ischemic stroke at $\mathbf{3}-\mathbf{6} \mathbf{~ h}$ after symptom onset. Neurocrit Care 2008; $8: 353-59$

29. Schellinger PD, Thomalla G, Fiehler J, et al. MRI-based and CT-based thrombolytic therapy in acute stroke within and beyond established time windows: an analysis of 1210 patients. Stroke 2007;38:2640-45

30. Thomalla G, Schwark C, Sobesky J, et al. Outcome and symptomatic bleeding complications of intravenous thrombolysis within 6 hours in MRI-selected stroke patients: comparison of a German multicenter study with the pooled data of ATLANTIS, ECASS, and NINDS tPA trials. Stroke 2006;37:852-58

31. Rowley HA. Extending the time window for thrombolysis: evidence from acute stroke trials. Neuroimaging Clin N Am 2005;15:575-87

32. Hacke W, Albers G, Al-Rawi Y, et al. The Desmoteplase in Acute Ischemic Stroke Trial (DIAS): a phase II MRI-based 9-hour window acute stroke thrombolysis trial with intravenous desmoteplase. Stroke 2005;36:66-73

33. Derex L, Nighoghossian N, Hermier M, et al. Influence of pretreatment MRI parameters on clinical outcome, recanalization and infarct size in 49 stroke patients treated by intravenous tissue plasminogen activator. J Neurol Sci 2004;225:3-9

34. Davis SM, Donnan GA, Parsons MW, et al. Effects of alteplase beyond $3 \mathbf{h}$ after stroke in the Echoplanar Imaging Thrombolytic Evaluation Trial (EPITHET): a placebo-controlled randomised trial. Lancet Neurol 2008; 7:299-309

35. Butcher KS, Parsons M, MacGregor L, et al. Refining the perfusion-diffusion mismatch hypothesis. Stroke 2005;36:1153-59

36. Butcher K, Parsons M, Allport L, et al. Rapid assessment of perfusion-diffusion mismatch. Stroke 2008;39:75-81

37. Lee KH, Lee SJ, Cho SJ, et al. Usefulness of triphasic perfusion computed tomography for intravenous thrombolysis with tissue-type plasminogen activator in acute ischemic stroke. Arch Neurol 2000;57:1000-08

38. Kloska SP, Dittrich R, Fischer T, et al. Perfusion CT in acute stroke: prediction of vessel recanalization and clinical outcome in intravenous thrombolytic therapy. Eur Radiol 2007;17:2491-98

39. MR and Recanalization of Stroke Clots Using Embolectomy (MR RESCUE). Available at: http://clinicaltrials.gov/ct2/show/NCT00389467. Accessed June 9, 2008

40. Qureshi AI, Suri MF, Nasar A, et al. Thrombolysis for ischemic stroke in the United States: data from National Hospital Discharge Survey 1999-2001. Neurosurgery 2005;57:647-54

41. Bose A, Henkes H, Alfke K, et al. The Penumbra System: a mechanical device for the treatment of acute stroke due to thromboembolism. AJNR Am J Neuroradiol 2008;29:1409-13

42. Rosamond W, Flegal K, Furie K, et al. Heart disease and stroke statistics-2008 update: a report from the American Heart Association Statistics Committee and Stroke Statistics Subcommittee. Circulation 2008;117:e25-146

43. Rosamond W, Flegal K, Friday G, et al. Heart disease and stroke statistics-2007 update: a report from the American Heart Association Statistics Committee and Stroke Statistics Subcommittee. Circulation 2007;115:69-171

44. Thom T, Haase N, Rosamond W, et al. Heart disease and stroke statistics-2006 update: a report from the American Heart Association Statistics Committee and Stroke Statistics Subcommittee. Circulation 2006;113:e85-151

45. Broderick J, Brott T, Kothari R, et al. The Greater Cincinnati/Northern Kentucky Stroke Study: preliminary first-ever and total incidence rates of stroke among blacks. Stroke 1998;29:415-21

46. Williams GR, Jiang JG, Matchar DB, et al. Incidence and occurrence of total (first-ever and recurrent) stroke. Stroke 1999;30:2523-28

47. Qureshi AI, Suri MF, Nasar A, et al. Changes in cost and outcome among US patients with stroke hospitalized in 1990 to 1991 and those hospitalized in 2000 to 2001. Stroke 2007;38:2180-84

48. Schneider AT, Kissela B, Woo D, et al. Ischemic stroke subtypes: a populationbased study of incidence rates among blacks and whites. Stroke 2004; 35:1552-56

49. Petty GW, Brown RD Jr, Whisnant JP, et al. Ischemic stroke subtypes: a population-based study of incidence and risk factors. Stroke 1999;30:2513-16

50. Kleindorfer D, Lindsell CJ, Brass L, et al. National US estimates of recombinant tissue plasminogen activator use: ICD-9 codes substantially underestimate. Stroke 2008;39:924-28

51. Morgenstern LB, Staub L, Chan W, et al. Improving delivery of acute stroke therapy: The TLL Temple Foundation Stroke Project. Stroke 2002;33:160-66

52. Acker JE 3rd, Pancioli AM, et al. Implementation strategies for emergency medical services within stroke systems of care: a policy statement from the 
American Heart Association/American Stroke Association Expert Panel on Emergency Medical Services Systems and the Stroke Council. Stroke 2007;38:3097-115

53. Lacy CR, Suh DC, Bueno M, et al. Delay in presentation and evaluation for acute stroke: Stroke Time Registry for Outcomes Knowledge and Epidemiology (S.T.R.O.K.E.). Stroke 2001;32:63-69

54. Stroke Unit Trialists' Collaboration. Collaborative systematic review of the randomised trials of organised inpatient (stroke unit) care after stroke. BMJ 1997;314:1151-59

55. Douglas VC, Tong DC, Gillum LA, et al. Do the Brain Attack Coalition's criteria for stroke centers improve care for ischemic stroke? Neurology 2005;64:422-27

56. Gropen TI, Gagliano PJ, Blake CA, et al. Quality improvement in acute stroke: the New York State Stroke Center Designation Project. Neurology 2006; $67: 88-93$

57. Alberts MJ, Hademenos G, Latchaw RE, et al. Recommendations for the establishment of primary stroke centers. Brain Attack Coalition. JAMA 2000; 283:3102-09

58. Alberts MJ, Latchaw RE, Selman WR, et al. Recommendations for comprehensive stroke centers: a consensus statement from the Brain Attack Coalition. Stroke 2005;36:1597-616

59. The Internet Stroke Center at Washington University in St. Louis. Stroke Center Directory. Available at: www.strokecenter.org/strokecenters.html. Accessed May 15, 2008.

60. Silverman IE, Beland DK, Chhabra J, et al. The “drip-and-ship" approach: starting IV t-PA for acute ischemic stroke at outside hospitals prior to transfer to a regional stroke center. Conn Med 2005;69:613-20

61. Jollis JG, Roettig ML, Aluko AO, et al. Implementation of a statewide system for coronary reperfusion for ST-segment elevation myocardial infarction. JAMA 2007;298:2371-80

62. MacKenzie EJ, Hoyt DB, Sacra JC, et al. National inventory of hospital trauma centers. JAMA 2003;289:1515-22

63. Suzuki S, Saver JL, Scott P, et al. Access to intra-arterial therapies for acute ischemic stroke: an analysis of the US population. AJNR Am J Neuroradiol 2004;25:1802-06

64. Connors JJ 3rd, Sacks D, Furlan AJ, et al. Training, competency, and credentialing standards for diagnostic cervicocerebral angiography, carotid stenting, and cerebrovascular intervention: a joint statement from the American Academy of Neurology, the American Association of Neurological Surgeons, the American Society of Interventional and Therapeutic Neuroradiology, the American Society of Neuroradiology, the Congress of Neurological Surgeons, the AANS/CNS Cerebrovascular Section, and the Society of Interventional Radiology. Neurology 2005;64:190-98

65. Higashida RT, Hopkins LN, Berenstein A, et al. Program requirements for residency/fellowship education in neuroendovascular surgery/interventional neuroradiology: a special report on graduate medical education. AJNR Am J Neuroradiol 2000;21:1153-59

66. Lewandowski CA, Frankel M, Tomsick TA, et al. Combined intravenous and intra-arterial r-TPA versus intra-arterial therapy of acute ischemic stroke: Emergency Management of Stroke (EMS) Bridging Trial. Stroke 1999; 30:2598-605

67. Jahan R, Duckwiler GR, Kidwell CS, et al. Intraarterial thrombolysis for treatment of acute stroke: experience in 26 patients with long-term follow-up. AJNR Am J Neuroradiol 1999;20:1291-99

68. Ramee SR, Subramanian R, Felberg RA, et al. Catheter-based treatment for patients with acute ischemic stroke ineligible for intravenous thrombolysis. Stroke 2004;35:109-11

69. Tissue plasminogen activator for acute ischemic stroke. The National Institute of Neurological Disorders and Stroke rt-PA Stroke Study Group. N Engl J Med 1995;333:1581-87

70. Clark WM, Wissman S, Albers GW, et al. Recombinant tissue-type plasminogen activator (Alteplase) for ischemic stroke 3 to 5 hours after symptom onset. The ATLANTIS Study: a randomized controlled trial. Alteplase Thrombolysis for Acute Noninterventional Therapy in Ischemic Stroke. JAMA 1999; 282:2019-26

71. Albers GW, Bates VE, Clark WM, et al. Intravenous tissue-type plasminogen activator for treatment of acute stroke: the Standard Treatment with Alteplase to Reverse Stroke (STARS) study. JAMA 2000;283:1145-50

72. Chiu D, Krieger D, Villar-Cordova C, et al. Intravenous tissue plasminogen activator for acute ischemic stroke: feasibility, safety, and efficacy in the first year of clinical practice. Stroke 1998;29:18-22

73. Zweifler RM, Brody ML, Graves GC, et al. Intravenous t-PA for acute ischemic stroke: therapeutic yield of a stroke code system. Neurology 1998;50:501-03

74. Grotta JC, Burgin WS, El-Mitwalli A, et al. Intravenous tissue-type plasminogen activator therapy for ischemic stroke: Houston experience 1996 to 2000. Arch Neurol 2001;58:2009-13

75. Kahn JH, Viereck J, Kase C, et al. The use of intravenous recombinant tissue plasminogen activator in acute ischemic stroke. J Emerg Med 2005;29:273-77

76. Arenillas JF, Ispierto L, Millan M, et al. Metabolic syndrome and resistance to IV thrombolysis in middle cerebral artery ischemic stroke. Neurology 2008;71: 190-95 